Глава 2. Интродукция и сортоизучение

\title{
ABOUT THE REPRODUCTIVE POTENTIAL IN WOODY PLANTS FROM SPIRAEOIDEAE SUBFAMILY IN THE CONDITIONS OF THE MIDDLE TAIGA SUBZONE IN THE KOMI REPUBLIC
}

\author{
Smirnova A. N. \\ Federal State Budgetary Scientific Institution \\ Federal Research Centre "Komi Scientific Centre \\ of the Ural Branch of the Russian Academy of Sciences" \\ Institute of Biology of Komi Scientific Centre \\ of the Ural Branch of the Russian Academy of Sciences \\ Syktyvkar, Russia, e-mail: smirnova@ib.komisc.ru
}

The subfamily Spiraeoideae includes many species that are valuable as ornamental woody and shrubby plants. In the arboretum of the Botanical Garden (Institute of Biology of Komi Scientific Centre), observations were made on plants from 51 Spiraeoideae taxa. The features of flowering and fruiting phases, as well as seed and vegetative reproduction indicators were studied in the conditions of the middle taiga subzone. Most of them (plants of 42 taxa) regularly bloom. From the fruit-bearing plants, 15 taxa have an annual abundant fruiting; three of them were recorded to have self-seeding. The germination rate of 11 species ranges from 69 to $87 \%$. The rootability of cuttings within root formation stimulators in individual species reaches $100 \%$, one species is intensively propagated by root growth. The peculiarities of the reproductive biology for Spiraeoideae subfamily representatives allow us to draw conclusions about their high reproductive potential in the new climatic conditions and the possibility of wider cultivation in the region.

Key words: Spiraeoideae, middle taiga subzone, introduction, Botanical garden, arboretum, flowering, fruiting.

удК 635.9

doi: 10.31360/2225-3068-2021-77-91-98

\section{ИНТРОДУКЦИЯ IRIS SETOSA В ЦЕНТРАЛЬНОЕ НЕЧЕРНОЗЕМЬЕ РОССИИ}

Сорокопудова О. А.

\author{
Федеральное государственное бюджетное \\ образовательное учреждение высшего образования \\ «Российский государственный аграрный университет - МСХА им. К. А. Тимирязева», \\ 2. Москва, Россия, e-mail: o.sorokopudova@rgau-msha.ru
}

Среди многообразия видов и сортов ирисов подрода Limniris вид Iris setosa Pall. ex Link (касатик щетинистый) редко используется в озеленении городов Центрального Нечерноземья России. В условиях влажного умеренно континентального климата растения этого вида зимостойки, устойчивы к гетероспориозу и полеганию, цветут с конца мая - в июне, с середины августа 
регулярно и обильно плодоносят, легко размножаются вегетативно делением куста и семенным путём. Приведены некоторые данные о строении побегов и генеративных органов. Подчеркнута целесообразность более широкого использования данного вида в озеленении, совмещения вегетативного и семенного размножения, деления растений через каждые 3-4 года, осенних сроков посевов семян для прохождения естественной стратификации, хранения семян при отрицательных температурах.

Ключевые слова: Iris setosa, декоративные многолетники, культивирование, фенология, морфология побегов, Центральное Нечерноземье.

Касатики, или ирисы (Iris L.) являются одними из ведущих декоративных многолетников в мире. Они издавна считались основой цветников. Несмотря на то, что период цветения отдельных видов и сортов не долог, путём подбора последовательно зацветающих ирисов можно успешно продлять этот период с конца весны до середины лета $[13,18]$. Iris setosa Pall. ex Link (касатик щетинистый) в природе обитает на северо-западе Северной Америки и северо-востоке Азии, отличается высоким полиморфизмом. Внутривидовые формы варьируют по плотности корневищ, числу и форме листьев различных формаций, высоте и строению цветоносного побега, ветвлению, числу цветков и их окраске, величине и форме коробочек $[1,2,5,6$, $10,11]$. В культуре возобновление и размножение вида практикуют делением куста и семенами.

Семенам многих видов касатиков, включая I. setosa, присущ средний или глубокий эндогенный физиологический тип покоя, связанный с пониженной ростовой активностью зародыша и недостаточной газопроницаемостью окружающих его тканей [9]. Для успешного прорастания семян I. setosa необходима длительная стратификация при низких положительных температурах (около 60 дней) [20] - короткая стратификация неэффективна [2]. Некоторые исследователи рекомендуют перед посевом семян удалять часть семенной кожуры у микропилярного отверстия или в зоне рубчика - этот приём обеспечивает повышение всхожести семян почти на $30 \%$ [2, 19]. Растения этого вида зимостойки (ареал вида простирается до северного полярного круга), устойчивы в культуре и по литературным данным перспективны для городского озеленения в Западной и Восточной Сибири, на северо-западе и юго-западе России $[10,11,14$, $15,17]$. Несмотря на неприхотливость и высокую способность к размножению в условиях Центрального Нечерноземья России касатик щетинистый культивируется редко. В цветочном оформлении чаще используются представители подрода Iris, главным образом ирисы 
Глава 2. Интродукция и сортоизучение

высокие бородатые (Iris $\times$ hybrida hort.), восприимчивые к гетероспориозу и полегающие в фазу цветения после обильных дождей [13].

Цель данной работы - дать характеристику растениям I. setosa в условиях Центрального Нечерноземья России.

Объекты и методы. Нами с 2014 г. проводилась работа по увеличению разнообразия видов ирисов подрода Limniris в коллекции Всероссийского селекционно-технологический институт садоводства и питомниководства (ВСТИСП) $[12,13]$. Для Москвы и Подмосковья характерен влажный умеренно континентальный климат. В данных условиях виды подрода Limniris особенно ценны благодаря устойчивости к гетероспориозу и полеганию. Семена I. setosa получены из ГБС РАН и посеяны осенью 2014 г. на интродукционном участке ВСТИСП для прохождения естественной стратификации. Почвы дерново-подзолистые. Двух-трёхлетние сеянцы из гряд переносили на участки с рядовым способом посадки по схеме $0,25 \times 0,8$ м. В начале весны вносили аммиачную селитру в качестве подкормки. Изучение особенностей цветения и плодоношения генеративных растений проводили с использованием методики фенологических наблюдений в ботанических садах [7] и методических указаний по семеноведению интродуцентов [8].

Результаты и их обсуждение. По нашим данным семена I. setosa, благодаря гетероспермии и глубокому покою, активно прорастали не только на следующий год, но и через год после их посева (рис. 1a). Длительное прорастание семян отмечено и у некоторых других видов ирисов подродов Iris и Limniris [15, 16, 21]. В генеративный период единичные растения вступали на второй год, большинство - на третий год после прорастания семян. У однолетних вегетативных розеточных побегов возобновления (побеги у I. setosa ди- или трициклические [15]) за вегетационный период развивается по 7-10 мечевидных ассимилирующих листьев, у цветоносов - по 3-4 листа. Годичные приросты (звенья) корневищ узкие, почти одинаковой толщины по всей длине. При ветвлении корневищ отрастающие побеги располагаются близко друг к другу, формируя плотную куртину (рис. 1б). Л. Л. Седельникова определила биоморфу ириса щетинистого как неявно полицентрическую [11]; по данным П. А. Павловой и Н. С. Даниловой в условиях Центральной Якутии растения данного вида могут произрастать на одном месте в питомнике несколько десятков лет [10]. Однако на основании нашего опыта можно рекомендовать производить деление куста не реже, чем через 3-4 года ввиду сложности раскорчёвки более взрослых растений. 
Цвели растения с конца мая - в июне, сроки цветения варьировали по годам в зависимости от метеорологических условий весеннего периода конкретных лет. В сформированной нами агроценопопуляции встречались генеты с сине-фиолетовыми и пурпурными околоцветниками диаметром 7-8 см, с сине-фиолетовыми цветками встречались чаще. Число цветков в соцветиях у среднегенеративных растений варьировало от 3 до 7. Высота растений составляла 65-90 см.

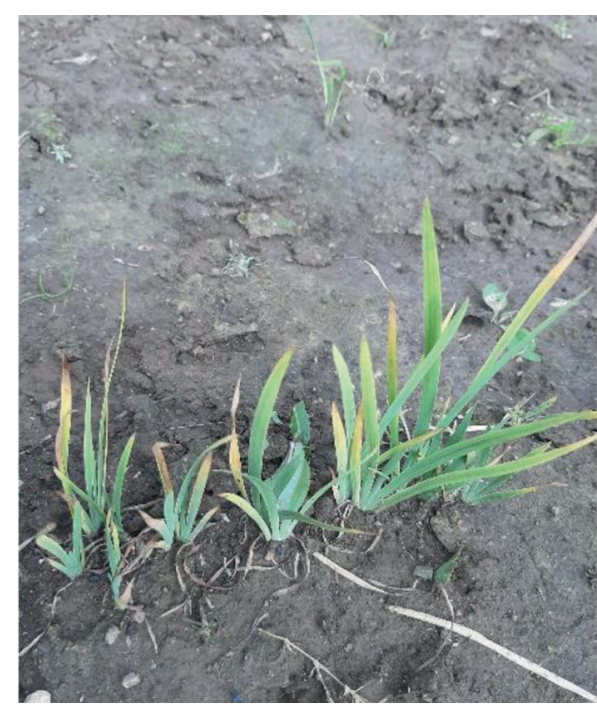

$a$

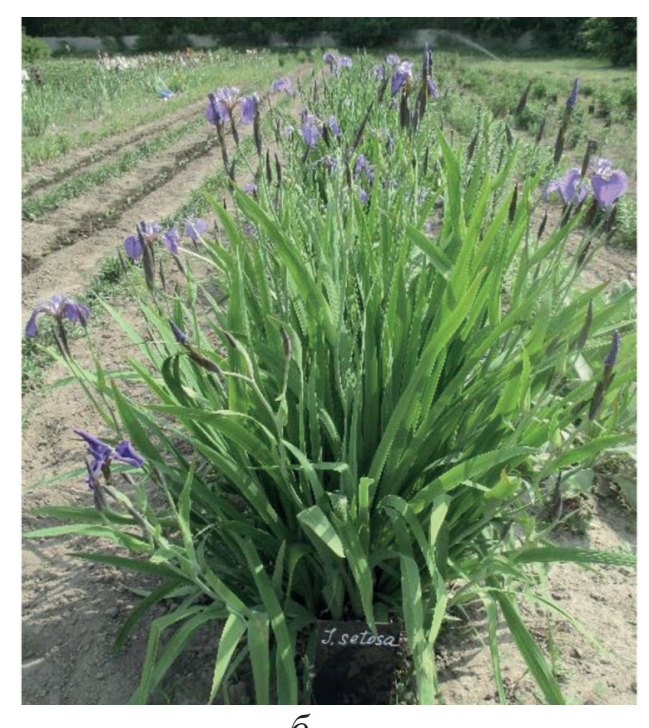

$\sigma$

Рис. 1. Внешний вид разновозрастных растений Iris setosa: $a$ - однолетние растения осенью, $\sigma$ - пятилетние генеративные растения в начале цветения

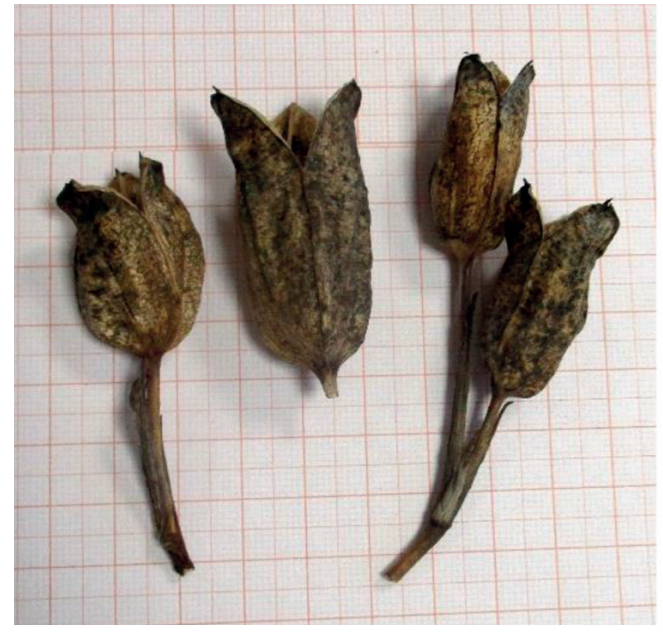

$a$

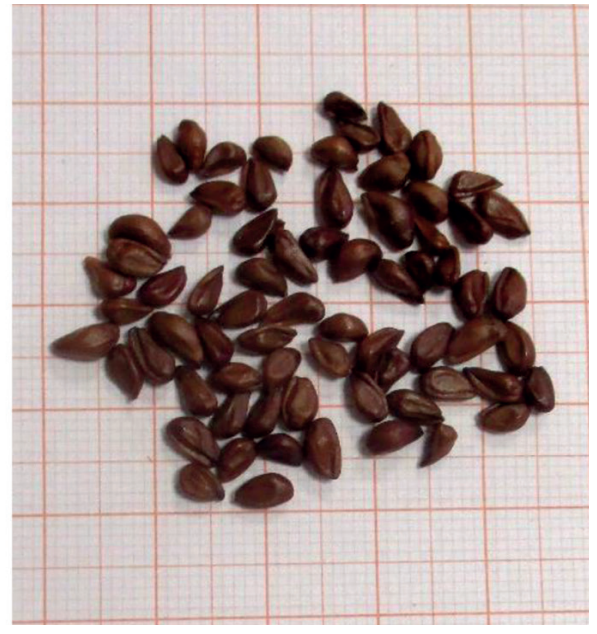

$\sigma$

Рис. 2. Плоды (a) и семена (б) Iris setosa 
Плодоношение во все годы наблюдений было регулярным и обильным. Коробочки I. setosa, развившиеся из первых цветков, достигали своей максимальной величины в конце цветения - через 3-4 недели после оплодотворения, начинали вскрываться с середины августа. Трещины доходили до 1/3 высоты плода с незначительным отклонением створок сверху (рис. 2a). Плоды по форме округло-продолговатые; их параметры составляли 1,2-2,0 × 3,0-5,0 см. Стенки перикарпия тонкие, светлеющие при созревании.

Семена I. setosa яйцевидные, слегка сдавленные с боков, неравнобокие, с килем с одной стороны, коричневые (от светлых до тёмных тонов), блестящие, с ровной однородной спермодермой (рис. 2б). Масса 1000 шт. семян - 9-12 г (крупнее, чем в созданной агроценопопуляции в Беларуси [3]). Минимальная масса семян зафиксирована в годы с наиболее высокими температурами в апреле-мае (2018-2019 гг.). Наиболее низкие показатели семенной продуктивности по нашим и литературным данным отмечались в засушливые годы, когда в европейской России наблюдалась наибольшая численность бронзовок (Cetonia spp.) - опылителей и одновременно вредителей, объедающих цветки I. setosa. В Центральной Якутии показатели семенной продуктивности у этого вида были ниже в природных местообитаниях, что вероятно связано с меньшим количеством потенциальных насекомых-опылителей в естественных биогеоценозах по сравнению с агрофитоценозом (табл. 1). Так как всхожесть семян I. setosa по данным Г. С. Бородич [3] резко падает через 3 года при содержании в комнатных условиях, рекомендуем через 2-3 месяца после их сбора переносить на хранение в морозильную камеру.

Таблийа 1

Семенная продуктивность

\section{I. setosa в некоторых регионах России}

\begin{tabular}{|c|c|c|c|c|}
\hline \multirow{2}{*}{ Регион } & \multirow{2}{*}{$\begin{array}{c}\text { В культуре } \\
\text { (К), } \\
\text { в природе } \\
(П)\end{array}$} & \multirow{2}{*}{ Год } & \multicolumn{2}{|c|}{$\begin{array}{c}\text { Реальная } \\
\text { семенная продуктивность }\end{array}$} \\
\hline & & & $\mathrm{X}$, шт./плод & $\mathrm{V}, \%$ \\
\hline \multirow{3}{*}{ Центральное Нечерноземье } & $\mathrm{K}$ & 2017 & $57,8 \pm 1,9$ & 14,5 \\
\hline & K & 2018 & $50,6 \pm 2,6$ & 20,4 \\
\hline & $\mathrm{K}$ & 2019 & $47,6 \pm 2,7$ & 22,8 \\
\hline Юго-Запад Черноземья ${ }^{1}$ & K & 2011 & $26,0 \pm 8,5$ & - \\
\hline \multirow{2}{*}{ Центральная Якутия ${ }^{2}$} & $\mathrm{~K}$ & 2009 & $44,2 \pm 4,6$ & 21,7 \\
\hline & $\Pi$ & 2009 & $12,1 \pm 2,6$ & 18,9 \\
\hline
\end{tabular}

Примечания: X - среднее значение со стандартной ошибкой;

$\mathrm{V}$ - коэффициент вариации;

1 - данные И. В. Шевченко [15],

2 - данные Д. В. Габышева [4]. 
Размножение семенами кроме высокой продуктивности позволяет увеличивать число вариантов генотипов, проводить отбор форм по ряду хозяйственно-ценных признаков (высоте побегов, срокам и продолжительности цветения, величине и окраске цветков и др.). При востребованности посадочного материала I. setosa на практике целесообразно комбинировать вегетативное и семенное размножение.

Заключение. Ввиду декоративности растений I. setosa в течение всего вегетационного периода, высокой зимостойкости, устойчивости к болезням и вредителям, неприхотливости в уходе, лёгкости в размножении семенным и вегетативных путём считаем возможным рекомендовать шире использовать этот вид в городских насаждениях Центрального Нечерноземья России.

С целью вегетативного размножения и сохранения растений на интродукционных участках, в ботанических садах, питомниках и других насаждениях целесообразно производить деление куста через каждые 3-4 года, вегетативное размножение совмещать с семенным для возможности отбора ценных генотипов. При длительном сохранении (более трёх лет) и накоплении семян следует использовать морозильные камеры.

\section{Библиографический список}

1. Алексеева Н.Б. О видах рода Iris L. (Iridaceae) из родства Iris setosa Pall. ex Link on the taxa of Iris setosa Pall. ex Link affinity (Iridaceae) // Turczaninowia. - 2013. - T. 16. № 2. - P. 13-29. - ISSN 1560-7259.

2. Андросова Д.Н., Данилова Н.С., Афанасьева Е.А. Влияние предпосевной обработки семян на всхожесть видов рода Iris // Наука и образование. - 2017. - № 4. - С. 109-113. ISSN 2073-8129.

3. Бородич Г.С. Всхожесть семян некоторых интродуцированных видов ирисов при длительном хранении // Hortus Botanicus. - 2020. - Т. 15. - С. 254-263. - doi: 10.15393/ j4.journal 4. Габышев Д.В. Семенная продуктивность некоторых видов растений флоры Центральной Якутии // Наука и образование. - 2011. - № 3 - - С. 40-44. - ISSN 2618-9712. 5. Данилова Н.С., Афанасьева Е.А., Борисова С.З. Интродукция ирисовых в Центральной Якутии // Политематический сетевой электронный научный журнал Кубанского государственного аграрного университета. - 2015. - № 111. - С. 1301-1315. - eISSN 1990-4665.

6. Илюшко М.В. Изменчивость касатика щетинистого Iris setosa Pall. ex Link на российском Дальнем Востоке: автореф. дис. ... канд. биол. наук. - Владивосток, 2000. - 27 с.

7. Методика фенологических наблюдений в ботанических садах СССР // Бюл. Гл. ботан. сада. - 1979. - Вып. 113. - С. 3-8.

8. Методические указания по семеноведению интродуцентов. - М.: Наука, 1980. - 64 с. 9. Николаева М.Г., Разумова М.В., Гладкова В.Н. Справочник по проращиванию покоящихся семян. - Л.: Наука, 1985. - 347 с.

10. Павлова П.А., Данилова Н.С. Интродукция касатика щетинистого (Iris setosa Pall. ex Link) в Центральной Якутии // Вестник КрасГАУ. - 2013. - № 7. - С. 94-99. - ISSN 1819-4036.

11. Седельникова Л.Л. Сезонный ритм развития и органогенез Iris setosa (Iridaceae) в лесостепной зоне Западной Сибири // Экосистемы. - 2019. - № 18. - С. 48-54. - ISSN 2414-4738. 
12. Сорокопудова О.А., Артюхова А.В. Коллекция ирисов в ФГБНУ ВСТИСП // Субтропическое и декоративное садоводство. - 2017. - Вып. 62. - С. 116-122. - ISSN 2225-3068. 13. Сорокопудова О.А., Артюхова А.В. Характеристика видов и сортов ирисов коллекции Всероссийского селекционно-технологического института садоводства и питомниководства // Сборник научных трудов Государственного Никитского ботанического сада. - 2019. - T. 148. - C. 235-245. - doi: 10.25684/NBG.scbook.148.2019.25.

14. Ткаченко К.Г. Виды рода Iris L. в коллекциях-экспозициях живых растений альпинария Ботанического сада Петра Великого Ботанического института РАН // Вестник Удмуртского университета. - 2013. - Вып. 3. - С. 35-43. - ISSN 2412-9518.

15. Шевченко И.В. Биоморфологические особенности видов и сортов Iris L. в культуре на юге Среднерусской возвышенности: дис. ... канд. биол. наук. - Белгород, 2013. - 160 с.

16. Шевченко И.В., Сорокопудова О.А. Особенности прорастания семян видов и сортов Iris L. в условиях ботанического сада Белгорода // Научные ведомости Белгородского государственного университета. Серия: Естественные науки. - 2012. - № 21-1(140). C. 100-106. - ISSN 2075-4671.

17. Шевченко И.В., Сорокопудова О.А. Цветение ирисов на юго-западе Черноземья // Вестник КрасГАУ. - 2010. - № 8(47). - С. 20-24. - ISSN 1819-4036.

18. Crisan I., Stoie A., Buta E., Cantor M. Flowering phenology of some Iris species in the UASVM Cluj agrobotanical garden // Romanian biotechnological letters. - 2018. - Vol. 23(3). - P. 13702-13707. [Electronic Resources]. - Access mode: https://www.researchgate.net/publication/327263160_Flowering_Phenology_of_Some_Iris_Species_in_the_UASVM_Cluj_ agrobotanical_garden (accessed: 10.02.2021).

19. Blumenthal A., Lerner H.R., Werker E., Poljakoff-Mayber A. Germination preventing mechanisms in iris seeds // Annals of Botany. - 1986. - Vol. 58. - Isee. 4. - P. 551-561. - doi: 10.1093/annbot/58.4.551.

20. Lee S.G., Kim H.Y., Lee K.Ch., Ku J.J. Effects of seed storage methods and shading on seed germination and seedling growth of endangered species, Iris dichotoma and Iris setosa // Journal of Korean forest society. - 2015. - Vol. 104. - No. 1. - P. 60-66. - doi: 10.14578/jkfs.2015.104.1.60. 21. Volis S., Dorman M. Effects of soil type, period of burial and moisture levels on the germination of Oncocyclus iris seeds // Plant Ecology. - 2019. - Vol. 220(11). - P. 1021-1028. - doi: 10.1007/s11258-019-00971-8.

\title{
CULTIVATION OF IRIS SETOSA IN THE CENTRAL NON-BLACK EARTH REGION OF RUSSIA
}

\section{Sorokopudova O. A.}

\author{
Federal State Budgetary Educational \\ Institution of Higher Professional Education \\ "Russian State Agrarian University - K. A. Timiryazev \\ Moscow Agricultural Academy", \\ Moscow, Russia, e-mail: o.sorokopudova@rgau-msha.ru
}

Among the variety of iris species and cultivars (subgenus Limniris), the species Iris setosa Pall. ex Link (beachhead iris) is rarely used in urban landscaping throughout the Central non-Black Earth region of Russia. In a humid temperate continental climate, 
Субтропическое и декоративное садоводство (77)

plants of this species are winter-hardy, resistant to heterosporiosis and lodging, and bloom from late May to June, from mid-August they bear fruit regularly and abundantly, as well as easily propagate vegetatively by dividing the bush and by seeds. Some data on the structure of shoots and generative organs are presented. The paper emphasized an expediency of wider use of this species in landscaping, combining vegetative and seed reproduction, division of plants every 3-4 years, autumn terms of sowing seeds for natural stratification, and storage of seeds at subzero temperatures.

Key words: Iris setosa, decorative perennials, cultivation, phenology, morphology of shoots, Central non-Black Earth Region.

УДК 635.977.1:581.6(470.21).(447.25) doi: 10.31360/2225-3068-2021-77-98-110

\title{
ВЕТРЕНИЦА ДЛИННОВОЛОСАЯ В УСЛОВИЯХ КИЕВА И КИРОВСКА (МУРМАНСКАЯ ОБЛ.)
}

Юдин С. И.

\author{
Федеральное государственное бюджетное научное учреждение \\ «Полярно-альпийский ботанический сад-институт им. Н. А. Аврорина \\ Кольского научного центра Российской академии наук», \\ 2. Кировск, Россия, e-mail: yudin.pabgi@yandex.ru
}

Представлены результаты многолетнего сравнительного изучения растений двух наиболее характерных для Горного Алтая экотипов (предгорного и высокогорного) Anemone narcissiflora subsp. crinita (Juz.) Kitag. в условиях Киева и Кировска (Мурманская обл.). Выявлены особенности ритмов сезонного развития, онтогенеза растений, прорастания семян этих экотипов в условиях первичной культуры. Сравнительное изучение условий произрастания in situ и ex situ, сезонного ритма, онтогенеза растений в одинаковых условиях первичной культуры позволяет выявить, что условиям высокогорий Алтая местообитанию изучаемых растений, в большей степени соответствуют условия северной тайги Хибинских гор Кольского полуострова. Установлено, что при интродукции в ПАБСИ растения ветреницы длинноволосой успешно проходят весь цикл развития, плодоносят, наблюдается самосев. Особенности роста и развития алтайских растений этого подвида ex situ свидетельствуют об успешной адаптации большинства из них в условиях Кольского Заполярья. Даны рекомендации по их размножению и выращиванию.

Ключевые слова: Anemone narcissiflora subsp. crinita (A. crinita Juz.), интродукция, экотип, Алтай, Украина, Кольский полуостров.

Наметившийся в последние десятилетия популяционный подход в интродукции растений способствует повышению эффективности этого процесса за счёт выявления потенциала, более полного охвата 